\title{
"I kind of feel like sometimes I am shoving it under the carpet”: Documenting women's experiences with post-abortion support in Ontario
}

\author{
Kathryn J. LaRoche ${ }^{a}$ and Angel M. Foster ${ }^{a b \star}$ \\ ${ }^{a}$ Faculty of Health Sciences, University of Ottawa, Ottawa, ON K1N 6N5, Canada; ${ }^{\text {Institute of }}$ \\ Population Health, University of Ottawa, Ottawa, ON K1N 6N5, Canada \\ *angel.foster@uottawa.ca.
}

\section{OPEN ACCESS}

\begin{abstract}
Citation: LaRoche KJ and Foster AM. 2017. "I kind of feel like sometimes I am shoving it under the carpet": Documenting women's experiences with post-abortion support in Ontario. FACETS 2: 754-763. doi: I 0.1 I39/ facets-2017-0059
\end{abstract}

Editor: James R. Woodgett

Received: May 29, 2017

Accepted: July 27, 2017

Published: October 3, 2017

Copyright: (c) 2017 LaRoche and Foster. This work is licensed under a Creative Commons Attribution 4.0 International License (CC BY 4.0), which permits unrestricted use, distribution, and reproduction in any medium, provided the original author(s) and source are credited.

Published by: Canadian Science Publishing

\begin{abstract}
Background: Abortion has been available without criminal restriction in Canada since 1988, and approximately 33000 terminations take place in Ontario each year.

Objectives: This study aimed to explore women's expressed desire for post-abortion support services, document the priorities expressed by women in seeking post-abortion support, and identify actionable strategies to improve post-abortion support services in Ontario.

Methods: Between 2012 and 2014 we conducted in-depth, open-ended interviews with 60 Anglophone women from across Ontario who had recently had an abortion. We aimed to rigorously explore the compounding issues of age and geography on women's abortion experiences. We analyzed our data for content and themes and reported on the findings related to post-abortion support.

Results: One third of our participants expressed a desire for post-abortion support, yet few were able to access a timely, affordable, non-directive service. Women were uncertain about how to find services; most contacted a provider recommended by the clinic or searched online. Women were enthusiastic about a talkline format citing anonymity and convenience as the main advantages.

Conclusion: Our results suggest that exploring ways to expand post-abortion support services in Ontario is warranted. A talkline format could provide an anonymous, convenient, non-judgmental, and non-directive way to address this unmet need.
\end{abstract}

Key words: pregnancy termination, Canada, reproductive health

\section{Introduction}

Abortion has been without criminal restriction in Canada for more than two decades and is one of the most common medical procedures experienced by women of reproductive age. Indeed, approximately 100000 abortions are performed each year, and one in three Canadian women will have an abortion during their lifetimes (Norman 2012; Canadian Institute for Health Information (CIHI) 2015). As Canada's most populous province, more than a third of the country's terminations take place in Ontario (CIHI 2015). Despite the prevalence of the procedure, the stigma surrounding abortion in the Canadian political and social climate often silences women's voices, leaving them with few opportunities to share and discuss their abortion experiences. Although there have been a number of attempts to pass anti-choice legislation at the federal level (National Abortion Federation 
Canada, n.d.), Ontario's policies have long been favorable toward abortion. However, policies are not the only driver of stigma (Kumar et al. 2009). The annual March for Life, the presence of protesters outside of abortion providing clinics, and the recent proliferation of crisis pregnancy centers (CPCs) characterize the abortion landscape in Ontario (LaRoche and Foster 2015; Mah 2017; Mallick 2017; The Canadian Press 2017). Notably, these dynamics do not surround other common, medically necessary procedures and likely contribute to both externalized and internalized stigma.

Although there is a substantial body of evidence from countries in which abortion is generally legally permitted to indicate that the majority of women do not experience negative mental health outcomes after an abortion (APA Task Force on Mental Health and Abortion 2008; Charles et al. 2008; Steinberg and Russo 2008; Major et al. 2009; Robinson et al. 2009; Munk-Olsen et al. 2011; Steinberg and Finer 2011), it has been shown that women can experience a complex range of emotions following a termination and may benefit from a space to talk about them (Weitz et al. 2008; Kimport et al. 2012).

In recent years, opponents of abortion rights in North America have made repeated attempts to tie abortion to a variety of mental health conditions (as reported by Kelly (2014), LaRoche and Foster (2015, 2016), Steinberg and Finer (2012), and Steinberg et al. (2012)). In fact, discussion of postabortion support in the public domain often centers on responding to "post-abortion trauma", "post-abortion syndrome", and "post-abortion stress". Although there is no evidence to support the existence of such "syndromes", these claims have had significant policy implications, particularly in the US, including the justification of mandatory information sessions and waiting periods for women seeking services in some states (Robinson et al. 2009; NARAL Pro-Choice America 2017). Furthermore, despite the overwhelming medical evidence to the contrary, some US states require clinicians to inform patients that abortion will result in an increased risk of mental health problems, including depression and suicidal ideation (Richardson and Nash 2006; Robinson et al. 2009). This information is in direct contrast with the official statement of the American Psychological Association, which has also strongly advised against mandated counseling for women seeking an abortion (APA Task Force on Mental Health and Abortion 2008).

Although we have not seen the same kinds of policies proposed or implemented in Canada, evidence suggests that the rhetoric that abortion is harmful to women is not limited to the US. In Ontario, CPCs perpetuate this message in both their services and online presence (LaRoche and Foster 2015, 2016) and share the resources and materials of their US counterparts. The same description of abortion being dangerous is a staple in the advertising campaigns of anti-abortion groups like the Canadian Centre for Bio-Ethical Reform and the Campaign Life Coalition (Saurette and Gordon 2016).

The narrative that abortion is a harmful procedure also ignores the extensive research that has been conducted on factors associated with post-abortion mental health. The literature demonstrates that the most significant predictors of post-abortion mental health are pre-abortion mental health and instances of violence (APA Task Force on Mental Health and Abortion 2008; Steinberg and Russo 2008; Munk-Olsen et al. 2011). However, research also shows that stigma and other social factors play a significant role in women's emotional outcomes following an abortion, which are distinct from mental health issues and should not be conflated. The decision-making process before the abortion, the process of finding social support afterward, feelings of stigma and the perceived need for secrecy, social disapproval, exposure to anti-abortion picketing and protesters, the loss of a romantic relationship, and emotional conflict surrounding the decision to terminate all play a large role in emotional outcomes following a termination (Major and Gramzow 1999; APA Task Force on Mental Health and Abortion 2008; Kimport et al. 2011; Kimport 2012). The important role of these social factors 
demonstrates why it is not surprising that some women would desire a space to discuss their experience free from judgment.

Yet, efforts to pathologize abortion have had a chilling effect such that it has become increasingly difficult to explore the full range women's experiences after an abortion. Indeed, the most prevalent social narratives about abortion outcomes are typically limited to regret or relief, even though some women fall in between on the emotional spectrum (Weitz et al. 2008). Talklines dedicated to postabortion support that aim to provide women with a space to process their emotions have emerged as a response to the increasingly polarized discourse. Kimport et al. (2012) investigated four of these talklines in the US. The authors conducted interviews and focus groups with staff members and volunteer counsellors from support talklines that varied in political stance, volume of callers served, and religious or secular orientation. In speaking with these counselors, the findings suggested that the stigma and silence that continue to surround abortion mean women have few spaces and opportunities to discuss their experiences. The counselors were in agreement that women need a space "devoid of politics for processing their experience and emotions over time" (Kimport et al. 2012 , p. 88). The authors found that talklines may be especially beneficial in creating a space for women to process the thoughts and feelings they may experience after a termination.

Despite this emerging literature about the importance of post-abortion support, to date, women's voices have been notably absent from the discussion. Furthermore, we know very little about what the demand and priorities are for this type of support in Canada as there is a lack of information that focuses on the Canadian context. This study aimed to address these gaps by documenting women's stories and exploring their experiences with post-abortion support in Ontario, Canada.

\section{Methods}

Between 2012 and 2014 we conducted in-depth, open-ended telephone interviews with 60 Anglophone women from across Ontario. All participants were age 18 and older, had obtained an abortion within five years of the interview, and resided in the Greater London, Ottawa, Thunder Bay, Timmins/North Bay, or Toronto regions at the time of the termination. We aimed to rigorously explore the compounding issues of age and geography on women's abortion experiences. This served as the first phase of a larger national study in which we interviewed 305 women from across all of Canada's provinces and territories (Cano and Foster 2016; Vogel et al. 2016; Foster et al. 2017).

We used a multimodal recruitment strategy that included placing social media ads, establishing a study website, circulating study information on listservs, and posting flyers in community venues. Women interested in participating contacted the study coordinator $(\mathrm{KL})$ who then conducted eligibility screening, provided additional information about the study and the consent form, and scheduled the interview on a first come/first served basis.

The principal investigator (AF), a medical anthropologist and medical doctor with longstanding experience undertaking qualitative research on abortion, and (or) a trained member of the all-woman study team conducted all interviews after obtaining informed consent. Interviewers used the same interview guide that asked participants a series of questions related to demographics, background, sexual, contraceptive, reproductive, and pregnancy history, as well as their general experiences accessing both primary and reproductive health services. We then asked participants about their abortion experience(s), including the circumstances surrounding the pregnancy and abortion, the process of locating a provider, scheduling an appointment, obtaining the service, and receiving follow-up care. We also asked women about their retrospective feelings about both the decision and the experience itself, as well as ways in which abortion services in Ontario could be improved. Interviews lasted an average of $60 \mathrm{~min}$, and with the permission of participants, we audio recorded and later transcribed 
them. Interviewers took notes during the interview and formally memoed shortly thereafter. All participants received a $\$ 40$ gift card to amazon.ca as a thank you for their time.

We began reviewing data as they were collected to identify common elements, draw initial connections between ideas, and establish thematic saturation. We conducted content and thematic analyses of interview content using both a priori (predetermined) categories and codes based on the research questions and inductive analysis techniques to identify emergent ideas. The content of the interviews combined with insights derived from the memos allowed for the creation of an initial code book which KL used to code all data. We used ATLAS.ti to manage our data, including our notes, memos, and transcripts. AF reviewed the codebook and coded transcripts. Guided by regular team meetings and discussion, our thematic analysis centered on grouping categories of information, drawing connections between ideas, and understanding relationships.

In this paper, we focus specifically on the findings related to post-abortion support. We have removed and (or) masked all personally identifying information and have used pseudonyms throughout. This study was approved by the Health Sciences and Sciences Research Ethics Board at the University of Ottawa (File \#H-08-12-08).

\section{Results}

\section{Participant characteristics}

Participants $(N=60)$ ranged in age from 18 to 48 and were evenly divided into two age cohorts: 18-24 (inclusive) and 25 and older at the time of the interview. The majority of participants selfidentified as white and all were Canadian citizens. Our 60 participants had 73 abortions since 1 January 2007; the overwhelming majority took place during the first trimester. The majority of women also had their abortions at freestanding clinics $(n=40)$ as compared with those who had their termination at a hospital $(n=21)$ or hospital-based clinic $(n=9)$. A minority of participants $(n=3)$ had medication abortions using the methotrexate/misoprostol regimen, provided either at a clinic, hospital, or doctor's office.

One third of participants expressed a desire for post-abortion support following their termination. These participants ranged in age from 18 to 48 years old and predominantly self-identified as white. These women's terminations also overwhelmingly took place during the first trimester and took place at a variety of facilities, including freestanding clinics, hospital-based clinics, and hospitals across all of the geographic regions we included in the study. Consistent with the overall sample, women who were interested in post-abortion support described a variety of circumstances leading up to, and a broad range of emotions after, their abortion. However, there were a number of themes that emerged in this subset of interviews which we detail below.

\section{Women's desire for post-abortion support was not associated with mental health issues}

I kind of feel like sometimes I am shoving it under the carpet... My parents don't even know. His parents don't know. So it's like, it's just one of those things. It's like I can't just talk about it to anybody. It's really hard because I feel like I want to keep it on the down low, but who else do I go to? Or [who] else is going to understand? (Alexis, aged 21, Ottawa)

Of the 20 women who were interested in post-abortion support services, only three described themselves as having a history of mental illness, specifically depression and anxiety. In two of these cases, women had a pre-existing relationship with a psychiatrist or psychologist and were disappointed in the reaction of the therapist to their disclosure of the abortion. 
Rather than the desire of post-abortion support being related to overarching mental health conditions, almost all of the women who desired post-abortion support described having a lack of social support. Women frequently mentioned the stigma that surrounds abortion. Taylor, a 28 -year-old woman from Ottawa who accessed services through her work benefits explained, "Now it's like talking about it helps to take away the shroud [of stigma]". Often women did not feel that the abortion was an appropriate topic of discussion to bring up with those whom they would have otherwise considered to be a source of emotional support. Other times, women felt that there was a lack of understanding of their experience from their partner, friends, and (or) family. Madison, aged 21, from Toronto, explained, "[Having post-abortion support provided] would have benefitted me in the sense [that when] I tried bringing it up to my boyfriend... he couldn't understand why I was getting so upset about it now".

For these reasons, women expressed an interest in having someone to talk to outside of their usual network of friends and (or) family. As Alice, a 30-year-old woman from North Bay, explained

If I had been given a counsellor's number, someone you know, whether it's a support group or anything to talk to, at that point I think would have been the ideal time... There was a few times during the first year or two where it was rough thinking about [the abortion]. But I wouldn't say I regret what I did, just maybe if I had someone to talk me through the emotional side of things.

Consistent with Alice's experience, the women we spoke to often noted that they did not regret the decision to terminate the pregnancy. Rather, women expressed regret and sadness about the life circumstances that necessitated or surrounded the abortion, not the abortion itself.

\section{Women had difficulty accessing desired services}

I definitely tried looking but I didn't really feel like I was finding... the right thing... Maybe I wasn't typing in the right thing [into the search engine]. But I felt like no matter how specific I was trying to get, I was... just finding random counselors and psychiatrists or psychologists. I wasn't really finding someone who maybe specializes... or, you know... people who have dealt with that kind of thing before. (Alexis, aged 21, Ottawa)

Despite their desire for post-abortion support, few women in our study were able to find and access desired services. Participants identified three methods of searching for post-abortion support services: searching online, calling the clinic where the procedure was performed, or calling their local public health unit (PHU). Women who had hospital-based abortions were especially likely to have contacted a PHU.

In searching online for available services, women found the abundance of anti-choice information on the internet to be challenging to sort through. When they searched for post-abortion support services, many women reported finding services that fell into one of two categories: paid for, clinical counseling services; or anti-choice/anti-abortion services, many of which were religiously affiliated. As described by Molly, aged 22, from London, "It's much easier to get information from a person than it is from a web page... On the internet there's basically websites that are telling you one thing, and then there's another website that's telling you the opposite. You have to interpret the information from both".

Several participants did access formal counseling services, but this was typically because of a preexisting referral to or a relationship with a mental health professional. Some other women were able to access these services through employee assistance programs or insurance benefits which helped to cover the cost. Women without supplemental insurance found both the cost and the wait times 
to be extremely prohibitive in accessing formal counseling services following their abortion. As Hannah, aged 35 and a resident of Ottawa at the time of her abortion, explained

I think that immediately after the procedure, maybe in the month or two right after... I think that would be the time to have access to counselors. Because I found that I had to wait-I think that I had to wait at least three weeks even to just have that one appointment... I only went once. And I think that the cost is difficult.

Several women also noted that they were unable to find a service that seemed specific enough for the kind of support they were looking for. Women explained that they were hesitant to access a general counseling service or general talkline for fear of judgment, or because they felt like there would be a lack of understanding of their experience.

\section{Women expressed considerable interest in non-directive, non-judgmental services}

I mean if [a talkline] was presented as this is a non-judgmental resource-it's anonymous, it's confidential for potential support-I mean that sounds pretty good, but at that time you know I think how isolated I was from support, I feel like anything could have helped. (Shannon, aged 25, Toronto)

Women identified several priorities for post-abortion services. Primarily, women noted confidentiality and (or) anonymity as a major concern. Closely linked with this was women's desire for a non-judgmental service. Women noted that abortion often felt like a taboo topic of discussion, and therefore, they wanted assurance that if they were discussing their experience, it was in a neutral space.

In addition, women wanted services that were either low cost or free. Many women cited financial constraints as one of the reasons for obtaining their abortion, and thus, having fees associated with post-abortion support services was prohibitive. As Erin, a 25 year old woman from Ottawa, explained, she was unable to access services following her termination because she lacked insurance coverage to help cover the costs:

I think that there should be more free counseling in regards to stuff like that, because in my opinion it's way too expensive. I... could have used counseling afterwards, but I didn't get any because I wasn't covered. I didn't have the money and [neither] did my parents.

Our participants were often enthusiastic about a talkline format of post-abortion support services as it combined anonymity, no cost, and increased flexibility for scheduling in comparison with an inperson service. About the talkline format, Erin went on to say that "Especially... [for] younger women [who] may not feel comfortable sitting in front of someone. Sometimes being behind a phone is easier, right? So a phone number... like a hotline or something like that. And not just for young girls [because] it's hard [for anyone] to talk about something like that".

\section{Discussion}

An August 2014 article published in the Washington Post urged both health care providers and prochoice organizations in the US to stop referring to abortion as a "difficult decision" for women (Harris 2014). The author argued that by assuming abortion is a difficult decision, we assume that women need help deciding and that this paves the way for mandated counseling laws. These laws are often based on medically inaccurate information and are designed to dissuade women from having 
abortions (Richardson and Nash 2006). The author also argued that the "abortion as a difficult decision" dialogue further stigmatizes the procedure.

Harris' point is well taken. The anti-choice movement in both the US and Canada has shifted its narrative from focusing on the fetus to focusing on women (Saurette and Gordon 2013). In this way, they have seized an "abortion harms women" message that presents abortion as a trauma and the decision to have one as tortured (Kelly 2014). This has certainly seeded efforts to impose restrictions on abortion access in the US (Richardson and Nash 2006; Lazzarini 2008) and has shaped public discourse and the activities of anti-choice groups across North America. Although it can be tempting to challenge one extreme with the other, Harris warns against this as well. Both versions of the polarized discourse-that abortion is always a difficult decision for women, or that it is never a difficult decision for women-are detrimental. In recent years, there have been efforts to acknowledge the range of emotions and pluralize women's experiences (Weitz et al. 2008).

That women express a range of emotions after an abortion-including feelings of sadness and isolation-is not surprising, and our findings with women in Ontario are consistent with the broader literature (Rocca et al. 2013). The experiences of our participants highlight that negative or complex emotions are distinct from mental illness and that a desire for support in the postabortion period is not a reflection of an underlying pathology. This distinction is important from both a policy and service delivery perspective, as well as from sociological and socio-cultural perspectives.

Our study found that there is a disconnect between women's expressed desire for post-abortion support services and the accessibility of these services in Ontario. Women consistently cited difficulty and (or) an inability to find post-abortion support that was low cost or free, did not have an extended wait time associated with it, and was confidential and non-judgmental. That these services also need to be structured in a way that is non-judgmental and woman centered is of primary importance.

\section{Limitations}

Qualitative methods provide an excellent mechanism for in-depth exploration of participants' experiences, beliefs, and behaviors. However, the method is not intended to yield representative and generalizable results. Although multimodal recruitment of a purposive sample of women who resided in Ontario at the time of their abortion gives us confidence that the themes we identified are significant, we are unable to assess the degree to which these experiences represent broader trends. In addition, by offering our participants a safe space to share their abortion story, the women that we spoke with may be more likely than the population at large to have expressed a desire for post-abortion support.

\section{Conclusions}

Our results suggest that exploring ways to expand post-abortion support in Ontario is warranted. Furthermore, in developing and expanding these services, women's preferences need to be considered. The talkline format could provide a viable way to offer post-abortion support while taking into account women's expressed priorities. Not only are talklines anonymous, which is important given the stigma that continues to surround abortion, but because women can call from anywhere or at different times of the day, this format provides increased convenience. Ensuring that these talkline services provide non-judgmental, non-directive, and medically accurate information and support is critical and could serve as a valuable resource for those women who self-identify as needing additional support in the post-abortion period. 


\section{Acknowledgements}

Ms. LaRoche received an Ontario Graduate Scholarship and several internal grants from the University of Ottawa that supported this project. Support for this project was also provided by a Faculty of Health Sciences Research Development Program grant and a grant from the Consortium national de formation en santé (CNFS) - Volet Université d'Ottawa. Dr. Foster's 2011-2016 Endowed Chair in Women's Health Research was funded by the Ministry of Health and Long-Term Care in Ontario, and we appreciate the general support for her time that made this project possible.

The study team thanks Emma Burgess, Lauren DeGroot, Julie El-Haddad, Jill Gedeon, Grace Sheehy, Kristina Vogel, and Sophia Zouheir for their contributions to the study and Drs. Paul Saurette and Raywat Deonandan for their input on earlier phases of this project. Both KL and AF had full access to all the data in the study and take responsibility for the integrity of the data and the accuracy of the data analysis. The conclusions and opinions expressed in this paper are those of the authors and do not necessarily represent the views of the organizations with which the authors are affiliated or the funders.

\section{Author contributions}

KJL and AMF conceived and designed the study. KJL and AMF performed the experiments/ collected the data. KJL and AMF analyzed and interpreted the data. KJL and AMF contributed resources. KJL and AMF drafted or revised the manuscript.

\section{Competing interests}

The authors have declared that no competing interests exist.

\section{Data accessibility statement}

All relevant data are within the paper.

\section{References}

APA Task Force on Mental Health and Abortion. 2008. Report of the APA Task Force on Mental Health and Abortion. American Psychological Association, Washington, DC [online]: Available from apa.org/pi/women/programs/abortion/mental-health.pdf.

Canadian Institute for Health Information (CIHI). 2015. Induced abortions reported in Canada in 2015 [online]: Available from cihi.ca/sites/default/files/document/induced-abortion-can-2015en-web.xlsx.

Cano JK, and Foster AM. 2016. "They made me go through like weeks of appointments and everything": documenting women's experiences seeking abortion care in Yukon Territory, Canada. Contraception, 94(5): 489-495. PMID: 27373541 DOI: 10.1016/j.contraception.2016.06.015

Charles VE, Polis CB, Sridhara SK, and Blum RW. 2008. Abortion and long-term mental health outcomes: a systematic review of the evidence. Contraception, 78(6): 438-450. PMID: 19014789 DOI: 10.1016/j.contraception.2008.07.005

Foster AM, LaRoche KJ, El-Haddad J, DeGroot L, and El-Mowafi IM. 2017. "If I ever did have a daughter, I wouldn't raise her in New Brunswick": exploring women's experiences obtaining abortion care before and after policy reform. Contraception, 95: 477-484. PMID: 28232129 DOI: 10.1016/j. contraception.2017.02.016 
Harris J. 15 August 2014. Stop calling abortion a 'difficult decision'. The Washington Post [online]: Available from washingtonpost.com/opinions/stop-calling-abortion-a-difficult-decision/2014/08/15/ e61fa09a-17fd-11e4-9349-84d4a85be981_story.html?utm_term=.b3b45a22a44e.

Kelly K. 2014. The spread of 'post abortion syndrome' as social diagnosis. Social Science \& Medicine, 102: 18-25. PMID: 24565137 DOI: 10.1016/j.socscimed.2013.11.030

Kimport K. 2012. (Mis)understanding abortion regret. Symbolic Interaction, 35(2): 105-122. DOI: $10.1002 /$ symb.11

Kimport K, Foster K, and Weitz TA. 2011. Social sources of women's emotional difficulty after abortion: lessons from women's abortion narratives. Perspectives on Sexual and Reproductive Health, 43(2): 103-109. PMID: 21651709 DOI: 10.1363/4310311

Kimport K, Perrucci A, and Weitz TA. 2012. Addressing the silence in the noise: how abortion support talklines meet some women's needs for non-political discussion of their experiences. Women \& Health, 52(1): 88-100. PMID: 22324360 DOI: 10.1080/03630242.2011.643348

Kumar A, Hessini L, and Mitchell EMH. 2009. Conceptualising abortion stigma. Culture, Health \& Sexuality, 11(6): 625-639. PMID: 19437175 DOI: 10.1080/13691050902842741

LaRoche KJ, and Foster AM. 2015. Toll free but not judgment free: evaluating postabortion support services in Ontario. Contraception, 92(5): 469-474. PMID: 26260687 DOI: 10.1016/j. contraception.2015.08.003

LaRoche KJ, and Foster AM. 2016. Exploring the online presence of organizations offering postabortion support services in Ontario. Frontiers in Women's Health, 1(1): 15-19. DOI: 10.15761/ FWH.1000106

Lazzarini Z. 2008. South Dakota's abortion script-threatening the physician-patient relationship. The New England Journal of Medicine, 359: 2189-2191. PMID: 19020321 DOI: $10.1056 /$ NEJMp0806742

Mah A. 21 April 2017. Ottawa abortion clinic says patients, staff at breaking point over protester intimidation. Ottawa Citizen [online]: Available from ottawacitizen.com/news/local-news/ ottawa-abortion-clinic-says-patients-staff-at-breaking-point-over-protester-intimidation.

Major B, and Gramzow RH. 1999. Abortion as stigma: cognitive and emotional implications of concealment. Journal of Personality and Social Psychology, 77(4): 735-745. PMID: 10531670 DOI: $10.1037 / 0022-3514.77 .4 .735$

Major B, Appelbaum M, Beckman L, Dutton MA, Russo NF, and West C. 2009. Abortion and mental health: evaluating the evidence. American Psychologist, 64(9): 863-890. PMID: 19968372 DOI: $10.1037 / 20017497$

Mallick H. 19 April 2017. Ottawa police won't protect abortion clinic despite pleas. Toronto Star [online]: Available from thestar.com/opinion/commentary/2017/04/19/ottawa-police-wont-protectabortion-clinic-despite-pleas-mallick.html.

Munk-Olsen T, Laursen TM, Pedersen CB, Lidegaard Ø, and Mortensen PB. 2011. Induced firsttrimester abortion and risk of mental disorder. The New England Journal of Medicine, 364(4): 332-339. PMID: 21268725 DOI: 10.1056/NEJMoa0905882 
NARAL Pro-Choice America. 2017. Who decides? The status of women's reproductive rights in the United States. 26th edition [online]: Available from prochoiceamerica.org/wp-content/uploads/ 2017/01/WhoDecides2017-DigitalEdition3.pdf.

National Abortion Federation Canada. n.d. Legal abortion in Canada [online]: Available from nafcanada.org/legal-abortion-ca.html.

Norman WV. 2012. Induced abortion in Canada 1974-2005: trends over the first generation with legal access. Contraception, 85(2): 185-191. PMID: 22036474 DOI: 10.1016/j.contraception.2011.06.009

Richardson CT, and Nash E. 2006. Misinformed consent: the medical accuracy of state-developed abortion counseling materials. Guttmacher Policy Review, 9(4): 6-11.

Robinson GE, Stotland NL, Russo NF, Lang JA, and Occhiogrosso M. 2009. Is there an "abortion trauma syndrome"? Critiquing the evidence. Harvard Review of Psychiatry, 17(4): 268-289. PMID: 19637075 DOI: 10.1080/10673220903149119

Rocca CH, Kimport K, Gould H, and Foster DG. 2013. Women's emotions one week after receiving or being denied an abortion in the United States. Perspectives on Sexual and Reproductive Health, 45(3): 122-131. PMID: 24020773 DOI: $10.1363 / 4512213$

Saurette P, and Gordon K. 2013. Arguing abortion: the new anti-abortion discourse in Canada. Canadian Journal of Political Science, 46(1): 157-185. DOI: 10.1017/S0008423913000176

Saurette P, and Gordon K. 2016. The changing voice of the anti-abortion movement: the rise of "prowoman" rhetoric in Canada and the United States. University of Toronto Press, Toronto, Ontario.

Steinberg JR, and Finer LB. 2011. Examining the association of abortion history and current mental health: a reanalysis of the National Comorbidity Survey using a common-risk-factors model. Social Science \& Medicine, 72(1): 72-82. PMID: 21122964 DOI: 10.1016/j.socscimed.2010.10.006

Steinberg JR, and Finer LB. 2012. Coleman, Coyle, Shuping, and Rue make false statements and draw erroneous conclusions in analyses of abortion and mental health using the National Comorbidity Survey. Journal of Psychiatric Research, 46(3): 407-411. PMID: 22348853 DOI: 10.1016/j. jpsychires.2012.01.019

Steinberg JR, and Russo NF. 2008. Abortion and anxiety: what's the relationship? Social Science \& Medicine, 67(2): 238-252. PMID: 18468755 DOI: 10.1016/j.socscimed.2008.03.033

Steinberg JR, Trussell J, Hall KS, and Guthrie K. 2012. Fatal flaws in a recent meta-analysis on abortion and mental health. Contraception, 86(5): 430-437. PMID: 22579105 DOI: 10.1016/j. contraception.2012.03.012

The Canadian Press. 29 May 2017. Ontario to create safe zones around abortion clinics. The Globe and Mail [online]: Available from theglobeandmail.com/news/national/ontario-to-create-safe-zonesaround-abortion-clinics/article35146225/.

Vogel KI, LaRoche KJ, El-Haddad J, Chaumont A, and Foster AM. 2016. Exploring Canadian women's knowledge of and interest in mifepristone: results from a national qualitative study with abortion patients. Contraception, 94(2): 137-142. PMID: 27125893 DOI: 10.1016/j.contraception.2016.04.008

Weitz TA, Moore K, Gordan R, and Adler N. 2008. You say "regret" and I say "relief": a need to break the polemic about abortion. Contraception, 78(2): 87-89. PMID: 18672107 DOI: 10.1016/j. contraception.2008.04.116 